\title{
Assessment of Premoli et al. Correlation Predictions in Horizontal Stratified-Wavy Two-Phase Flow Encountered at Small Diameter T-Junction
}

\author{
Georgios K. Makrygiannis, Dionissios P. Margaris
}

\begin{abstract}
Two-phase flow is present in many and of different kind of industrial applications, especially in the form of gas-liquid two-phase flow. Despite of its common occurrence, its understanding is quite limited in comparison to single-phase flow due to its complexity. One critical parameter to characterize a gas-liquid two-phase flow and thereby to appropriate size the required industrial equipment is void fraction. The latter is affected by flow rates, fluid properties and flow gradient, whereas in turn it influences other important flow parameters such as pressure drop and heat transfer among others. Though there is available a plethora of void fraction correlations, most of them are limited to be accurate for similar fluid flow problems to that developed for, and thus they cannot be considered suitable to be utilised irrespective of the applied inlet conditions. However, a slip ratio correlation proposed by Premoli et al. has been proven quite accurate in void fraction predictions, and thus it is recommended to be used in case of horizontal and upward inclined pipes regardless the established flow regime, whereas its implementation does not require complex or iterative procedure to be performed. This hypothesis was evaluated by conducting numerical analysis and comparing the obtained results for void fraction, average velocity, and two-phase mixture density with the corresponding predictions of Premoli et al. correlation. It was found that in general Premoli et al. correlation over predicts the void fraction and average water velocity values, while under predicts the average air velocity and two-phase mixture density. However, the observed error does not indicate that the adoption of Premoli et al. correlation is a mistaken option a priori with the final choice of its usage being determined by the desired accuracy required from the application.
\end{abstract}

Index Terms-CFD model, two-phase flow, void fraction, Premoli et al. correlation.

\section{INTRODUCTION}

Multiphase flow can be defined as the concurrent flow of more than one of any of the three discrete physical phases of matter or a combination thereof, whereas its occurrence range from simple natural processes to complex industrial applications, especially in the form of two-phase flow.

Two-phase flow can be considered as the most common class of multiphase flows and includes gas-solid, gas-liquid, and liquid-liquid flows. In spite of its common presence, the understanding is quite limited in comparison to single-phase

Georgios K. Makrygiannis, Department of Mechanical Engineering and Aeronautics, University of Patras, Patras, Greece

Dionissios P. Margaris, Department of Mechanical Engineering and Aeronautics, University of Patras, Patras, Greece flow due to its nature [1]. Among two-phase flows the gas-liquid flow is probably the most important due to its existence in many industrial processes and to the comprised characteristics of a deformable interface as well as to the compressibility of one of the co-existing phases. Moreover, the interfacial distribution that occurs during two-phase flow leads to the formation of flow structures called flow regimes, which in case of horizontal flow can be bubbly, stratified (or stratified-wavy), intermittent (slug and/or plug), or annular flow regime, whereas the developed flow regime is depended on parameters such as flow rates, fluid properties, and pipe geometry [2]. Once the phases' redistribution is known, the two-phase flow phenomenon may be simplified and dealt in a similar way to single-phase flow [3].

One crucial parameter in any gas-liquid system that is affected by flow rates, fluid properties and flow gradient is the void fraction [4], [5], which in turn is a key parameter for sizing the entire equipment of industrial applications by influencing important flow parameters such as pressure drop and heat transfer among others [3].

There is a plethora of available void fraction correlations but most of them are limited to the fluid flow problems developed for (i.e. flow patterns, gas and liquid flow rates, and pipe geometries), and thereby they cannot be considered robust and suitable to be utilised irrespective of the applied inlet conditions. However, according to extensive comparison works of available void fraction correlations such as the work presented by Woldesemayat and Ghajar [3], who performed a comparative analysis of sixty-eight void fraction correlations against a wide range of experimental data, Premoli et al. correlation is found to be as accurate in void fraction predictions as the drift-flux correlations, and thus it is recommended to be utilised in case of horizontal and upward inclined pipes regardless the established flow regime. In addition, Premoli et al. correlation does not require a complex or iterative procedure to be performed facilitating thereby its adoption.

In this perspective, the present study aimed to assess via direct comparison with numerical data the predictive capability and thus the applicability of Premoli et al. correlation to estimate important two-phase flow parameters apart from void fraction in a stratified-wavy horizontal air-water two-phase flow. The computational model generated to conduct the numerical analysis was first validated in order to ensure the robust and accurate predictions of numerical modelling, whereas its scale was dictated by the observed lack of published data regarding the 


\section{Assessment of Premoli et al. Correlation Predictions in Horizontal Stratified-Wavy Two-Phase Flow Encountered at Small Diameter T-Junction}

study of small diameter T-junctions which can lead to scaling down the size of industries manufacture or process hazardous materials according to Stacey et al. [6].

\section{VOID FRACTION CORRELATIONS}

Void fraction is a crucial parameter in characterizing a two-phase flow in any gas-liquid system, whereas the determination of the value of other important two-phase flow parameters such as average velocity, two-phase mixture density, pressure drop, among others, requires prior the effective calculation of the void fraction value. Despite that there are numerous of void fraction correlations available in the literature none of them can be considered universal and adequate to be utilised irrespective of the applied fluid flow conditions (i.e. gas-liquid flow rates and flow pattern). Most of the correlations are limited to the features of the problem developed for (e.g. flow pattern dependent), whereas others require complex iterative schemes to be performed.

In general, the void fraction correlations can be classified into four categories according to Vijayan et al. [7] which are: a) slip ratio correlations in which the void fraction is calculated as a function of a constant term, mixture quality, gas and liquid densities, and gas and liquid viscosities, b) $k \cdot a_{H}$ correlations in which the void fraction is calculated based on the homogeneous void fraction, $a_{H}$, multiplied by a constant term that has either a fixed value or is a function of fluid flow parameters depending on the applied correlation, c) drift flux correlations in which the void fraction is calculated based on a distribution parameter and the drift velocity, and finally d) miscellaneous empirical correlations which does not meet the criteria to be classified into previous categories and they are empirical in nature.

\section{A. Premoli et al. correlation}

It is a slip ratio correlation presented by Premoli et al. [8] and it calculates the void fraction accounting for the effect of mass flux. It is primarily proposed to be utilised in annular flow regime, but it is also considered a reliable approach in any other flow regime. The latter feature as well as the simple and quite straightforward calculation procedure of void fraction have made the present correlation a common practice according to literature [9], [10]. In order to implement the correlation, one should apply the equations given below.

$$
\begin{gathered}
a=\frac{x}{x+s[1-x)\left(\frac{p_{L}}{p_{L}}\right]} \\
S=1+E_{1}\left[\frac{y}{1+\left(y E_{2}\right)}-\left(y E_{2}\right)\right]^{0.5} \\
y=\frac{\beta}{1-\beta} \\
\beta=\frac{1}{1+\left(\frac{1-x}{x}\right)\left(\frac{p_{L}}{\rho_{L}}\right)} \\
E_{1}=1.578 \operatorname{Re}_{L}^{-0.19}\left(\frac{\rho_{L}}{\rho_{L}}\right)^{0.22} \\
E_{2}=0.0273 \operatorname{Re}_{L}^{-0.51} W e_{L}\left(\frac{\rho_{L}}{\rho_{L}}\right)^{-0.08} \\
R e_{L}=\frac{G D}{\mu_{L}}
\end{gathered}
$$

$$
W e_{L}=\frac{G^{2} D}{\sigma p_{L}}
$$

where $x$ is the mixture quality, $\rho_{G}$ and $\rho_{L}$ are the densities of the corresponding gas and liquid phase of the mixture and $R e_{L}$ and $W e_{L}$ are the Reynolds and Weber numbers, respectively.

\section{B. Wallis Correlation}

It is an empirical correlation in nature that calculates the void fraction shown in (9) as a function of the Lockhart-Martinelli parameter $X_{t t}$, which in turn is a function of the ratios of the gas and liquid viscosities, gas and liquid densities, and mixture quality. Owing to that there are not any limitations in its application, the present correlation was used to validate the numerical predictions before the latter being compared with the corresponding predictions of Premoli et al. correlation.

$$
\begin{gathered}
a=\left(1+X_{\mathrm{tt}}^{0.9}\right)^{-0.38} \\
X_{\mathrm{tt}}=\left(\frac{\mu_{L}}{\mu_{L}}\right)^{0.1}\left(\frac{1-x}{x}\right)^{0.9}\left(\frac{\rho_{L}}{\rho_{L}}\right)^{0.5}
\end{gathered}
$$

\section{COMPUTATIONAL MODEL}

Nowadays, computational fluid dynamics (CFD) software packages such as the ANSYS Fluent software utilised to perform the current study provide end-users with the ability to handle complex flow phenomena in a robust, accurate and fast manner. More specifically, the computational models and meshes required to perform the numerical analysis were created in the Design Modeler and the Ansys Meshing applications of the referred software, whereas all simulations were carried out in Fluent.

Each computational model was consisted of main and run arm pipes placed in a horizontal position and having a diameter of $20 \mathrm{~mm}$, and a regular T-junction (i.e. with an equal diameter to main and run arm pipes) with an upward and vertical oriented side arm, Fig. 1. The current configuration was also adopted to study the separation performance of the regular T-junction which is beyond of the scope of the present paper and thus it would not be further discussed. The major dimensions of the computational models created are presented in Table 1 .

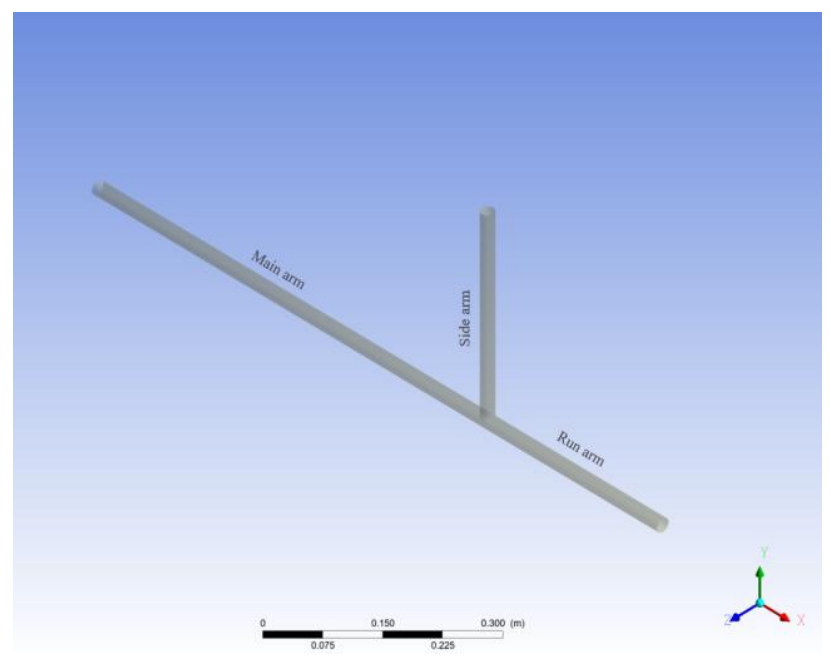

Fig. 1. Computational model created to conduct the numerical analysis. 
Table 1. Major dimensions of the generated computational models.

\begin{tabular}{|c|c|}
\hline Main arm length $(\mathrm{mm})$ & 700 \\
\hline Run arm length $(\mathrm{mm})$ & 300 \\
\hline Side arm length $(\mathrm{mm})$ & 300 \\
\hline Pipe diameter $(\mathrm{mm})$ & 20 \\
\hline Overall length $(\mathrm{mm})$ & 1100 \\
\hline
\end{tabular}

The generated computational mesh was consisted of approximately 500,000 tetrahedral and hexahedral elements, Fig. 2, with its final mesh dense being determined by mesh independence study [11]. It is worth to be noted that the computational mesh was created accounting for the applied turbulence closure method and the desired $\mathrm{y}^{+}$value in order to obtain accurate results.

As regards the simulations, a transient and turbulent air-water flow was considered, whereas the multiphase and turbulence models used were the Volume of Fluid (VOF) and the Realizable $\mathrm{k}-\varepsilon$, respectively. The Realizable $\mathrm{k}-\varepsilon$ turbulence model constitutes a common practice according to literature since it is both adequate to capture the generated turbulence structures and less computationally expensive in comparison with other available turbulence models such as the Standard k- $\omega$ and the SST k- $\omega$ models. Moreover, it has been proven that the choice of turbulence model affects less the accurate prediction of phases' redistribution and consequently the value of important two-phase flow parameters such as void fraction [12], [13]. Concerning the discretization schemes, the Body Force Weighted and the Compressive schemes were utilised for the pressure discretization and for the volume of fluid, respectively, whereas the Second Order Upwind scheme was used for the remaining variables. The pressure and velocity fields were coupled using the PISO algorithm, whereas the transient time formulation was achieved by applying the Bounded Second Order Implicit scheme. The simulation setup settings are summarized in Table 2.

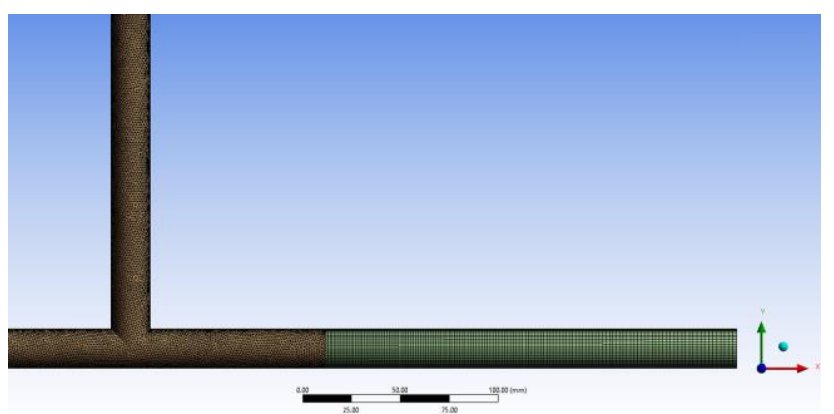

Fig. 2. Computational mesh generated by utilizing tetrahedral and hexahedral elements.

Table 2. Simulation setup settings utilised in the numerical study.

\begin{tabular}{|c|c|}
\hline Turbulence model & Realizable k- $\varepsilon$ \\
\hline Pressure & Body force weighted \\
\hline Volume fraction & Compressive \\
\hline Momentum & Second order upwind \\
\hline Turbulent kinetic energy & Second order upwind \\
\hline Turbulent dissipation rate & Second order upwind \\
\hline Pressure-velocity coupling & PISO \\
\hline Transient formulation & $\begin{array}{c}\text { Bounded second } \\
\text { order implicit }\end{array}$ \\
\hline
\end{tabular}

\section{RESUlTs AND Discussion}

As it is mentioned above, an air-water two-phase flow in a circular cross-section pipeline system of $20 \mathrm{~mm}$ diameter in conjunction with a regular $\mathrm{T}$-junction was considered and it was studied for various inlet flow conditions. More specifically, nine distinct flow conditions (i.e. test cases) were examined with the corresponding values of the air and water superficial velocities tabulated on Table 3. It should be noted that either air, $V_{s a}$, or water, $V_{s w}$, superficial velocity represents the velocity of the corresponding fluid if it was the only fluid flowing into the pipe. Moreover, the established flow regime for each test case was a stratified-wavy as depicted in Fig. (3) - (5).

Table 3. Inlet flow conditions considered in the present study.

\begin{tabular}{|c|c|c|}
\hline Test case $(\mathrm{TC})$ & $V_{s a}(\mathrm{~m} / \mathrm{s})$ & $V_{s w}(\mathrm{~m} / \mathrm{s})$ \\
\hline \multirow{2}{*}{ TC1 } & \multirow{3}{*}{3.65} & 0.442 \\
\cline { 1 - 1 } TC2 & & 0.884 \\
\cline { 1 - 1 } TC3 & \multirow{3}{*}{4.53} & 1.77 \\
\cline { 1 - 1 } TC4 & & 0.442 \\
\hline TC5 & \multirow{3}{*}{8.16} & 0.884 \\
\hline TC6 & 1.77 \\
\hline TC7 & & 0.442 \\
\hline TC8 & & 0.884 \\
\hline TC9 & & 1.77 \\
\hline
\end{tabular}
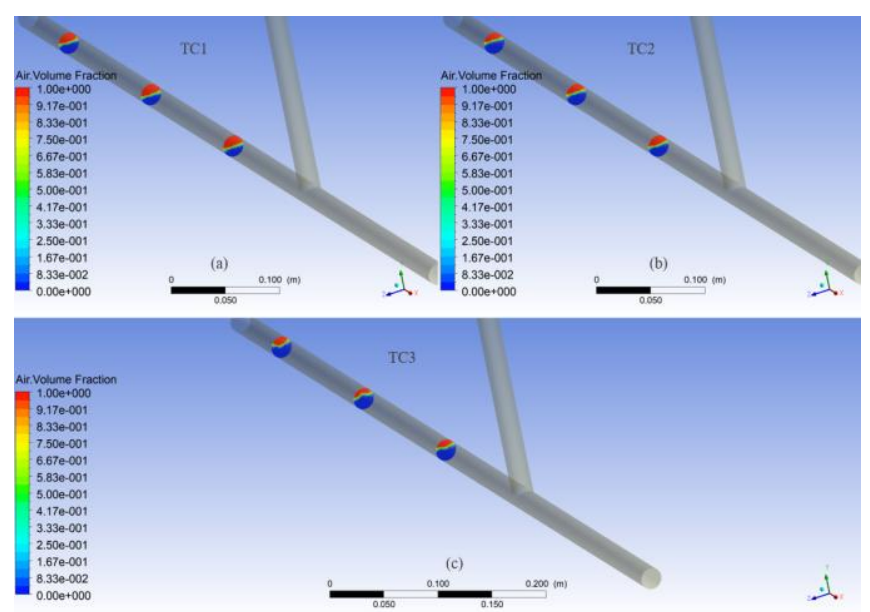

Fig. 3. Stratified-wavy flow regime established for a constant air superficial velocity of $3.65 \mathrm{~m} / \mathrm{s}$ and for (a) $V_{s w}=0.442$ $\mathrm{m} / \mathrm{s}$, (b) $V_{s w}=0.884 \mathrm{~m} / \mathrm{s}$, and (c) $V_{s w}=1.77 \mathrm{~m} / \mathrm{s}$, shown at three circular planes along the main arm pipe. 


\section{Assessment of Premoli et al. Correlation Predictions in Horizontal Stratified-Wavy Two-Phase Flow Encountered at Small Diameter T-Junction}
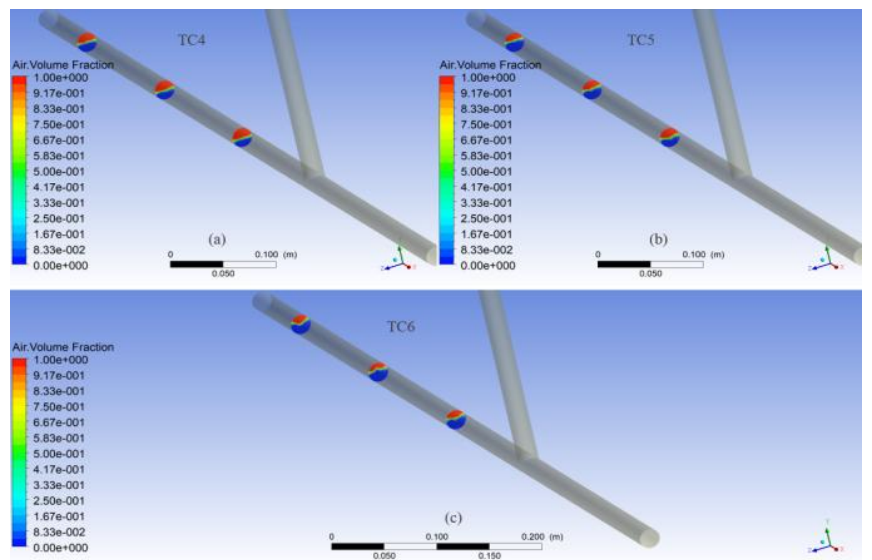

Fig. 4. Stratified-wavy flow regime established for a constant air superficial velocity of $4.53 \mathrm{~m} / \mathrm{s}$ and for (a) $V_{s w}=0.442$ $\mathrm{m} / \mathrm{s}$, (b) $V_{s w}=0.884 \mathrm{~m} / \mathrm{s}$, and (c) $V_{s w}=1.77 \mathrm{~m} / \mathrm{s}$, shown at three circular planes along the main arm pipe.
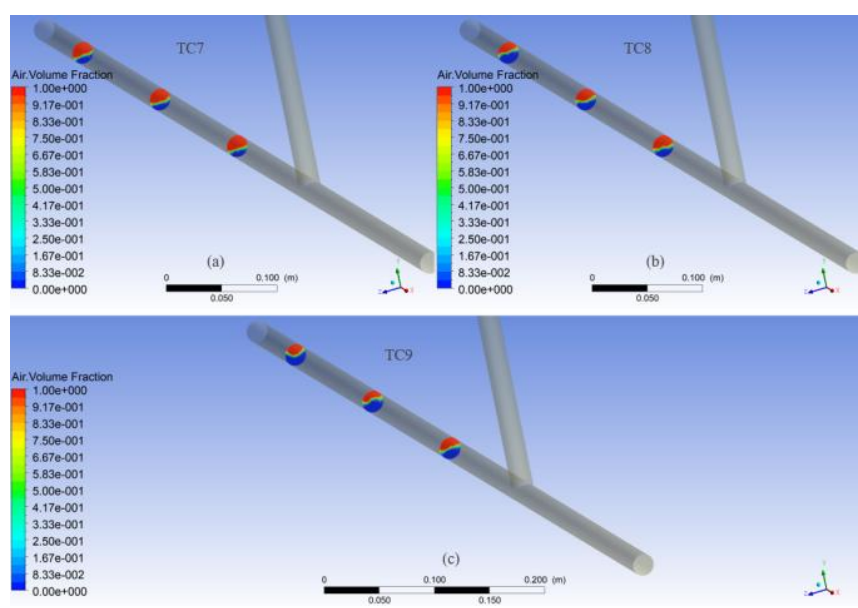

Fig. 5. Stratified-wavy flow regime established for a constant air superficial velocity of $8.16 \mathrm{~m} / \mathrm{s}$ and for (a) $V_{s w}=0.442$ $\mathrm{m} / \mathrm{s}$, (b) $V_{s w}=0.884 \mathrm{~m} / \mathrm{s}$, and (c) $V_{s w}=1.77 \mathrm{~m} / \mathrm{s}$, shown at three circular planes along the main arm pipe.

\section{A. Validation of the computational model}

In order to assess the predictive capability of the computational model, its void fraction values were compared to the corresponding ones arised from the Wallis correlation. Table 4 summarizes the void fraction values resulted from the implementation of both approaches, whereas Table 5 shows the quality of the computational void fraction predictions evaluated in terms of absolute error, $e$, and root-mean-square (RMS) value, which are calculated by using the expressions shown in (11) and (12), respectively.

$$
\begin{gathered}
e=\left|a_{\text {cale }}-a_{\text {pred }}\right| \\
\text { RMS }=\left[\frac{1}{N-1} \sum_{i=1}^{N}\left(\frac{a_{\text {raili } i}-a_{\text {predi } i}}{a_{\text {predi }}}\right)^{2}\right]^{0.5} \times 100 \%
\end{gathered}
$$

where $a_{\text {calc }}$ is the computational void fraction value, $a_{\text {pred }}$ is the predicted void fraction value, and $\mathrm{N}$ are the number of the simulations performed.

The values of the absolute error as well as the RMS value in all test cases under consideration clearly indicate the capability of the computational model to correctly estimate the void fraction and thus its suitability to be used for comparing the void fraction values predicted from Premoli et al. correlation.

Table 4. Void fraction predictions resulted from the implementation of both CFD model and Wallis correlation.

\begin{tabular}{|c|c|c|}
\hline Test case (TC) & CFD model & Wallis correlation \\
\hline TC1 & 0.609 & 0.616 \\
\hline TC2 & 0.525 & 0.532 \\
\hline TC3 & 0.463 & 0.453 \\
\hline TC4 & 0.632 & 0.642 \\
\hline TC5 & 0.551 & 0.558 \\
\hline TC6 & 0.484 & 0.477 \\
\hline TC7 & 0.717 & 0.712 \\
\hline TC8 & 0.627 & 0.629 \\
\hline TC9 & 0.559 & 0.545 \\
\hline
\end{tabular}

Table 5. Illustration of the quality of the CFD void fraction predictions.

\begin{tabular}{|c|c|c|}
\hline Test case (TC) & $e$ & RMS (\%) \\
\hline TC1 & $6.60 \mathrm{E}-03$ & \\
\hline TC2 & $7.09 \mathrm{E}-03$ & \\
\hline TC3 & $9.59 \mathrm{E}-03$ & \\
\hline TC4 & $9.55 \mathrm{E}-03$ & \multirow{2}{*}{1.59} \\
\hline TC5 & $6.53 \mathrm{E}-03$ & \\
\hline TC6 & $6.99 \mathrm{E}-03$ & \\
\hline TC7 & $5.49 \mathrm{E}-03$ & \\
\hline TC8 & $1.90 \mathrm{E}-03$ & \\
\hline TC9 & $1.37 \mathrm{E}-02$ & \\
\hline
\end{tabular}

Fig. 6 depicts the variation of void fraction in case of increasing water superficial velocity (i.e. increasing water volumetric flow rate) under a constant air superficial velocity (i.e. constant air volumetric flow rate). It is observed that the void fraction decreases as the water superficial velocity increases for a given air superficial velocity, while the void fraction increases as the air superficial velocity increases for a given water superficial velocity.

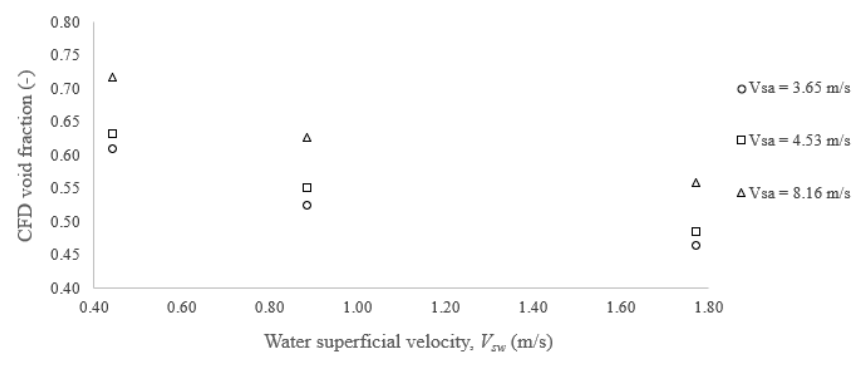

Fig. 6. Variation of the CFD void fraction in all test cases examined.

\section{B. Predictive capability of Premoli et al. correlation}

Table 6 summarizes the void fraction values predicted by Premoli et al. correlation as well as the corresponding void fraction values resulted from the implementation of the computational model. It can be seen that in general the Premoli et al. correlation over predicts the void fraction for all test cases examined, whereas looking at Fig. 7 a similar behavior is observed for both CFD and Premoli et al. correlation regarding the variation of void fraction, namely a decrease on the void fraction as the water superficial velocity increases under a constant air superficial velocity and an 
increase on the void fraction as the air superficial velocity increases under a constant water superficial velocity.

Table 6. Void fraction predicted by both CFD model and Premoli et al. correlation.

\begin{tabular}{|c|c|c|}
\hline Test case (TC) & CFD model & $\begin{array}{c}\text { Premoli } \text { et al. } \\
\text { correlation }\end{array}$ \\
\hline TC1 & 0.609 & 0.652 \\
\hline TC2 & 0.525 & 0.574 \\
\hline TC3 & 0.463 & 0.481 \\
\hline TC4 & 0.632 & 0.683 \\
\hline TC5 & 0.551 & 0.610 \\
\hline TC6 & 0.484 & 0.522 \\
\hline TC7 & 0.717 & 0.759 \\
\hline TC8 & 0.627 & 0.702 \\
\hline TC9 & 0.559 & 0.631 \\
\hline
\end{tabular}

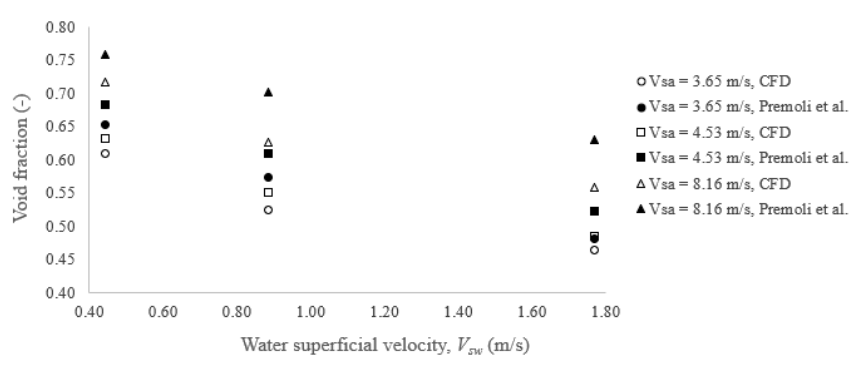

Fig. 7. Variation of void fraction resulted from the implementation of both CFD model and Premoli et al. correlation.

The quality of the Premoli et al. correlation predictions was also evaluated by calculating the absolute error and the RMS value shown in Table 7 . These values indicate that the current correlation is not a mistaken option a priori since the error is less than $10 \%$ and thereby it can be used to estimate the void fraction regardless the established flow regime as also reported by Woldesemayat and Ghajar [3].

Table 7. Illustration of the quality of the predicted void fraction by adopting Premoli et al. correlation.

\begin{tabular}{|c|c|c|}
\hline Test case (TC) & $e$ & RMS (\%) \\
\hline TC1 & $4.33 \mathrm{E}-02$ & \\
\hline TC2 & $4.89 \mathrm{E}-02$ & \\
\hline TC3 & $1.81 \mathrm{E}-02$ & \multirow{2}{*}{8.70} \\
\hline TC4 & $5.08 \mathrm{E}-02$ & \\
\hline TC5 & $5.88 \mathrm{E}-02$ & \\
\hline TC6 & $3.78 \mathrm{E}-02$ & \\
\hline TC7 & $4.17 \mathrm{E}-02$ & \\
\hline TC8 & $7.48 \mathrm{E}-02$ & \\
\hline TC9 & $7.20 \mathrm{E}-02$ & \\
\hline
\end{tabular}

It is interesting to examine how the error on void fraction prediction affects the value of other important two-phase flow parameters such as average velocity and two-phase mixture density. The average gas and liquid phase velocities are used to calculate the slip ratio, $S$, and thereby to characterize the two-phase flow, whereas the two-phase mixture density is required in calculation of two-phase pressure drop which in turn is a key parameter for the proper design and safe operation of processes involving two-phase flow. The air and water average velocities, $u_{a}$ and $u_{w}$, can be defined as the ratio of either corresponding air or water superficial velocity divided by the void fraction or the liquid holdup, respectively, and they can be calculated as show in (13) and (14), whereas the two-phase mixture density, $\rho_{m}$, is given in (15) and it constitutes the standard calculation approach according to literature [14].

$$
\begin{gathered}
u_{a}=\frac{V_{w a}}{\sigma} \\
u_{W}=\frac{V_{w W}}{1-\sigma} \\
p_{m}=p_{a} a+P_{W}(1-a)
\end{gathered}
$$

where $\rho_{a}$ and $\rho_{w}$ correspond to the density of air and water in atmospheric conditions, and they are considered equal to $1.204 \mathrm{~kg} / \mathrm{m}^{3}$ and $998.2 \mathrm{~kg} / \mathrm{m}^{3}$, respectively, for the purposes of the present study.

Table $8-10$ tabulate the results obtained from both CFD model and Premoli et al. correlation regarding average air and water velocities, and two-phase mixture density, while they also depict the comparison of the adopted approaches in terms of RMS value. It can be observed that in general the Premoli et al. correlation under predicts the average air velocity, Table 8 , while over predicts the average water velocity, Table 9. This behavior is expected on the one hand due to the previously obtained results for the void fraction and on the other hand due to the expressions from which the average air and water velocities were calculated. Regarding the two-phase mixture density, it is underestimated with an RMS error slightly above $15 \%$. Although the resulted RMS values are greater than that observed in void fraction predictions, their magnitude cannot be considered as prohibitive for the implementation of Premoli et al. correlation.

Table 8. Comparison of average air velocity predicted by both CFD model and Premoli et al. correlation.

\begin{tabular}{|c|c|c|c|}
\hline \multirow{2}{*}{$\begin{array}{c}\text { Test case } \\
\text { (TC) }\end{array}$} & \multicolumn{2}{|c|}{$u_{a}(\mathrm{~m} / \mathrm{s})$} & \multirow{2}{*}{ RMS (\%) } \\
\cline { 2 - 3 } & CFD model & $\begin{array}{c}\text { Premoli } \text { et al. } \\
\text { correlation }\end{array}$ & \\
\hline TC1 & 5.99 & 5.60 & \multirow{2}{*}{} \\
\hline TC2 & 6.95 & 6.36 & \multirow{2}{*}{9.58} \\
\hline TC3 & 7.88 & 7.59 & \multirow{2}{*}{} \\
\hline TC4 & 7.17 & 6.63 & \\
\hline TC5 & 8.22 & 7.43 & \\
\hline TC6 & 9.36 & 8.68 & \\
\hline TC7 & 11.4 & 10.8 & \\
\hline TC8 & 13.0 & 11.6 & \\
\hline TC9 & 14.6 & 12.9 & \\
\hline
\end{tabular}

Table 9. Comparison of average water velocity predicted by both CFD model and Premoli et al. correlation.

\begin{tabular}{|c|c|c|c|}
\hline \multirow{2}{*}{$\begin{array}{c}\text { Test case } \\
\text { (TC) }\end{array}$} & \multicolumn{2}{|c|}{$u_{w}(\mathrm{~m} / \mathrm{s})$} & \multirow{2}{*}{ RMS (\%) } \\
\cline { 2 - 3 } & CFD model & $\begin{array}{c}\text { Premoli } \text { et al. } \\
\text { correlation }\end{array}$ & \\
\hline TC1 & 1.13 & 1.27 & \multirow{2}{*}{13.88} \\
\hline TC2 & 1.86 & 2.07 & \\
\hline TC3 & 3.30 & 3.41 & \multirow{2}{*}{13.39} \\
\hline TC4 & 1.20 & 1.39 & \\
\hline TC5 & 1.97 & 2.27 & \\
\hline
\end{tabular}



Small Diameter T-Junction

\begin{tabular}{|l|l|l|}
\hline TC6 & 3.43 & 3.70 \\
\cline { 1 - 2 } TC7 & 1.56 & 1.83 \\
\hline TC8 & 2.37 & 2.96 \\
\hline TC9 & 4.01 & 4.80 \\
\end{tabular}

Table 10. Comparison of two-phase mixture density predicted by both CFD model and Premoli et al. correlation.

\begin{tabular}{|c|c|c|c|}
\hline \multirow{2}{*}{$\begin{array}{c}\text { Test case } \\
\text { (TC) }\end{array}$} & \multicolumn{2}{|c|}{$\rho_{m}\left(\mathrm{~kg} / \mathrm{m}^{3}\right)$} & \multirow{2}{*}{ RMS (\%) } \\
\cline { 2 - 3 } & CFD model & $\begin{array}{c}\text { Premoli } \text { et al. } \\
\text { correlation }\end{array}$ & \\
\hline TC1 & 391.0 & 347.9 & \\
\hline TC2 & 474.8 & 426.0 & \multirow{2}{*}{16.35} \\
\hline TC3 & 536.6 & 518.5 & \\
\hline TC4 & 368.1 & 317.5 & \\
\hline TC5 & 448.9 & 390.2 & \\
\hline TC6 & 515.7 & 478.0 & \\
\hline TC7 & 283.4 & 241.8 & \\
\hline TC8 & 373.1 & 298.5 & \\
\hline TC9 & 440.9 & 369.1 & \\
\hline
\end{tabular}

\section{CONCLUSION}

The ubiquitous existence of two-phase flow and the complexity of underlying the phases' redistribution process in any gas-liquid system led the research community to address the emerged problem by developing empirical correlations to predict critical fluid flow parameters such as void fraction. Accurate predictions of void fraction are critical since they determine the design of the entire system by influencing other important flow parameters such as pressure drop and heat transfer. Despite the plethora of available void fraction correlations, most of them have limited accuracy for a wide range of fluid flow conditions. However, there are empirical approaches such as Premoli et al. correlation that are recommended to be utilised regardless of the applied inlet conditions.

This hypothesis was evaluated by conducting numerical analysis and comparing the Premoli et al. correlation predictions of void fraction, average velocity, and two-phase mixture density against numerical results. The two-phase flow considered was an air-water flow in a horizontal pipeline system of $20 \mathrm{~mm}$ diameter in conjunction with a regular T-junction, whereas the established flow pattern was stratified-wavy.

The results showed that in general Premoli et al. correlation over predicts the void fraction and average water velocity values, while under predicts the average air velocity and two-phase mixture density. However, the error that slightly exceeds $15 \%$ in case of two-phase mixture density predictions, while it is less than $10 \%$ for void fraction predictions indicates that the use of Premoli et al. correlation cannot be discarded a priori and it can be adopted to estimate important two-phase flow parameters taking into account the required final accuracy of the calculations, which is dictated by the application.

\section{ACKNOWLEDGMENT}

This research is co-financed by Greece and the European Union (European Social Fund - ESF) through the
Operational Programme "Human Resources Development, Education and Lifelong Learning" in the context of the project "Strengthening Human Resources Potential via Doctorate Research" (MIS-5000432), implemented by the State Scholarships Foundation (IKY).
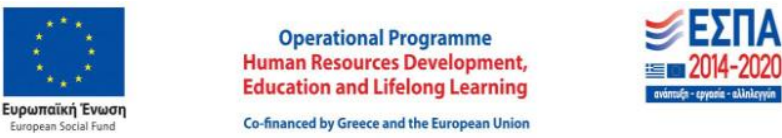

\section{REFERENCES}

[1] N. Ratkovich, S. K. Majumder, T. R. Bentzen. (2013, June). Empirical correlations and CFD simulations of vertical two-phase gas-liquid (Newtonian and non-Newtonian) slug flow compared against experimental data of void fraction. Chemical Engineering Research and Design. 91(6), 988-998. Available: https://doi.org/10.1016/j.cherd.2012.11.002

[2] N. Shao, A. Gavriilidis, P. Angeli. (2009, June). Flow regimes for adiabatic gas-liquid flow in microchannels. Chemical Engineering Science. 64(11), 2749-2761. Available: https://doi.org/10.1016/j.ces.2009.01.067

[3] M. A. Woldesemayat, A. J. Ghajar. (2007, April). Comparison of void fraction correlations for different flow patterns in horizontal and upward inclined pipes. International Journal of Multiphase Flow. $33(4)$, 347-370 Available: https://doi.org/10.1016/i.ijmultiphaseflow.2006.09.004

[4] T. R. Butler, X. Chen, and J. P. Brill, "Ratio-arm bridge capacitance transducer for two-phase flow measurements," $41^{\text {st }}$ International Instrumentation Symposium, Auora, United States (USA), 1995.

[5] P. Andreussi, K. Bendiksen. (1989, November-December). An investigation of void fractions in liquid slugs for horizontal and inclined gas-liquid pipe flow. International Journal of Multiphase Flow. 15(6), 937-946. Available: https://doi.org/10.1016/0301-9322(89)90022-0

[6] T. Stacey, B. J. Azzopardi, G. Conte. (2000, May). The split of annular two-phase flow at a small diameter T-junction. International Journal of Multiphase Flow. 26(5), 845-856. Available: https://doi.org/10.1016/S0301-9322(99)00051-8

[7] P. K. Vijayan, A. P. Patil, D. S. Pilkhwal, D. Saha, V. Venkat Raj. (2000, November). An assessment of pressure drop and void fraction correlations with data from two-phase natural circulation loops. Heat and Mass Transfer. 36, 541-548. Available: https://doi.org/10.1007/s002310000108

[8] A. Premoli, D. Francesco, and A. Prina, "An empirical correlation for evaluating two-phase mixture density under adiabatic conditions," European Two-Phase Flow Group Meeting, Milan, Italy, 1970.

[9] G. Baker, Separation and control of gas-liquid flows at horizontal T-junctions (Ph.D. Thesis). University of Nottingham, Nottingham, 2003.

[10] E. M. K. Wren, Geometric effects on phase split at a large diameter T-Junction (Ph.D. Thesis). University of Nottingham, Nottingham, 2001.

[11] G. K. Makrygiannis, and D. P. Margaris, "Two- and three- dimensional computational investigation of the separation efficiency of an air-water mixture flowing through an inclined T-junction branch," $8^{\text {th }}$ International Conference on Experiments/Process/System Modeling/Simulation/Optimization, Athens, Greece, 2019.

[12] M. Gourma, P. G. Verdin. (2016, November). Two-phase slug flows in helical pipes: Slug frequency alterations and helicity fluctuations. International Journal of Multiphase Flow. 86, 10-20. Available: https://doi.org/10.1016/j.ijmultiphaseflow.2016.07.013

[13] L. Xing, H. Yeung, J. Shen, Y. Cao. (2013, July). Numerical study on mitigating severe slugging in pipeline/riser system with wavy pipe International Journal of Multiphase Flow. 53, 1-10. Available: https://doi.org/10.1016/j.ijmultiphaseflow.2013.01.003

[14] A. J. Ghajar, S. M. Bhagwat. (2013, April). Effect of void fraction and two-phase dynamic viscosity models on prediction of hydrostatic and frictional pressure drop in vertical upward gas-liquid two-phase flow. Heat Transfer Engineering. 34(13), 1044-1059. Available: https://doi.org/10.1080/01457632.2013.763541 


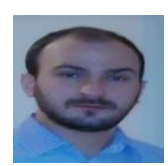

Georgios K. Makrygiannis born in Agrinio, Greece on August $17^{\text {th }}, 1989$. He did his diploma in Mechanical Engineering and Aeronautics Department at the University of Patras, Greece, graduating in 2013. Then, he started his MSc studies in Water Resources and Environmental Engineering at the Department of Civil Engineering at the University of Patras, Greece, where he studied numerically the Fluid Structure Interaction (FSI) between sea waves and a spar-buoy wind turbine platform. His research activity was financed by the State Scholarships Foundation (IKY) which implemented the Action "Scholarships Programmes by the State Scholarships Foundation" which was under the framework of the Operational Program "Education and Life Long Learning", co-financed by the European Social Fund and the Public Investments Programme. Since 2015, he is a Ph.D. candidate at the Department of Mechanical Engineering and Aeronautics at the University of Patras, Greece, and his research activity is focusing on experimental and numerical investigation of phase separation of gas-Newtonian liquid two-phase flows occurred at small diameter T-junctions.

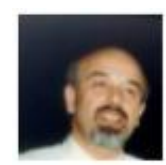

Dionissios P. Margaris born in Zakynthos island, Greece on September $28^{\text {th }}$, 1953. He is Professor in Mechanical Engineering and Aeronautics Department at the University of Patras, Greece, and Head of the Fluid Mechanics Laboratory (FML). His research activities are multiphase flows including gas-liquid-solid particles flows, gas-liquid air lift pump performance, centrifugal and T-junction separation modelling, as well as experimental and theoretical investigations of hot air dehydration of agricultural products, capillary pumped loops, steady and transient flows in pipes and networks. Also, he is dealing with fluid dynamics analysis of wind turbines, aero-acoustic analysis, and environmental impacts of wind turbines. He has participated in over 130 international conferences and he has over 80 publications on high-interested impact factor journals, whereas he has participated in several research projects supported by HAI, GSRT, CEC-THERMIE, whereas he is member of AIAA, AHS, ASME and EUROMECH unions as well as of TCG (Technical Chamber of Greece). 